\title{
Secretory Phospholipase A2 Digital Expression Analysis in Colon Adenocarcinoma
}

\author{
EVANGELOS FALIDAS ${ }^{1}$, EIRINI KITSIOULI ${ }^{2 *}$, DESPOINA SPYROPOULOU ${ }^{3 *}$, \\ EVANGELOS TSIAMBAS ${ }^{4}$, ASIMINA KALOGIROU ${ }^{5}$, GEORGE TSOUVELAS ${ }^{6}$, \\ STYLIANOS PAPADOPOULOS ${ }^{2}$, MICHAIL MITSIS ${ }^{7}$, MARILENA LEKKA ${ }^{2}$, SOFIANIKI MASTRONIKOLI ${ }^{8}$, \\ DIMITRIOS PESCHOS ${ }^{9}$, ODYSSEAS DIMAS ${ }^{10}$ and KONSTANTINOS VLACHOS ${ }^{7}$ \\ ${ }^{1}$ Department of Surgery, Halkida General Hospital, Halkida, Greece; \\ ${ }^{2}$ Laboratory of Biochemistry, Chemistry Department, University of Ioannina, Ioannina, Greece; \\ ${ }^{3}$ Department of Radiation Oncology, Medical School, University of Patras, Patras, Greece; \\ ${ }^{4}$ Department of Cytology, 417 VA (NIMTS) Hospital, Athens, Greece; \\ ${ }^{5}$ Department of Pathology, Halkida General Hospital, Halkida, Greece; \\ ${ }^{6}$ Department of Nursing, University of West Attica, Athens, Greece; \\ ${ }^{7}$ Department of Surgery, University Hospital of Ioannina, University of Ioannina, Ioannina, Greece; \\ ${ }^{8}$ Brighton and Sussex Medical School, Brighton, U.K.; \\ ${ }^{9}$ Department of Physiology, Medical School, University of Ioannina, Ioannina, Greece; \\ ${ }^{10} 2^{\text {nd }}$ Department of Internal Medicine, "Gennimatas" General Hospital, Athens, Greece
}

\begin{abstract}
Background/Aim: Phospholipases A2 represent a family of enzymes that regulate the metabolism of phospholipids by hydrolyzing them into fatty acids. Secretory phospholipase A2 (SPLA2) catalyzes the calcium-dependent 2-acyl groups hydrolysis to produce 3-sn-phosphoglycerides. This study aimed to investigate SPLA2 expression in colon adenocarcinoma (CA). Materials and Methods: Thirty $(n=30)$ formalin-fixed, paraffin-embedded primary CA tissue sections were used and analyzed. Immunohistochemistry was performed using an anti-SPLA2 antibody. Digital image analysis was also implemented for evaluating objectively the corresponding protein expression levels. Results: Increased SPLA2 protein expression (high \& moderate immunostaining levels) was observed in 23/30 (76.6\%) cases, whereas 7/30 (23.4\%) CA tissues demonstrated low protein levels. High expression levels were detected in 9/30 (30\%) cases. SPLA2 overall expression was strongly associated with tumor
\end{abstract}

This article is freely accessible online.

*These Authors equally contributed to this study.

Correspondence to: Evangelos Tsiambas, MD, MSc, Ph.D., 17 Patriarchou Grigoriou E' Street, Ag. Paraskevi, 15341 Athens, Greece. Tel: +30 2106526259, e-mail: tsiambasecyto@yahoo.gr

Key Words: Carcinoma, colon, phospholipase, immunohistochemistry, oxidative stress. diameter $(p=0.004)$, whereas other statistically significant associations were not observed (stage: $p=0.971$, inflammatory infiltration: $p=0.795$; carcinoma location: $p=0.340$; differentiation grade: $p=0.748$; sex: $p=0.369$; ulceration: $p=0.433)$. Conclusion: SPLA2 over-expression is observed in significant subsets of CAs correlating with advanced tumor growth progression (increased diameter). SPLA2 seems to influence endogenous cell responses by its crucial enzymatic activity and can potentially be a biomarker for monitoring CA patients.

Among biochemical and metabolic deregulations that occur in the intra-cellular micro-environment during the carcinogenic process, fatty acid catabolism is a crucial procedure combined or not with oxidative stress $(1,2)$. Fatty acid hydrolysis is mediated by phospholipases, especially of type A2 (3). These enzymes catalytically hydrolyze the corresponding bonds and result in the release of arachidonic and lysophosphatidic acids (4). Molecules such as leukotrienes and prostaglandins demonstrate significant inflammatory activity (5). Concerning phospholipases A2, their pro-enzymes are activated by trypsin. Additionally, His48/Asp-99/calcium complex is involved in significant biochemical reactions in the exocrine pancreatic region (6). Secretory phospholipase A2 (SPLA2) gene (PLA2G10 gene band: 16p13.12) encodes for the corresponding protein- a member of phospolipase enzymes family. It functions predominantly in insulin metabolism and resistance rates and it is also involved in atherosclerosis and response to 
inflammation (7). It is also well known that SPLA2 aberrant expression is correlated with deregulation of the autophagy mechanism and hydrolysis of surfactant phospholipids in neonates (8). In them, retreatment with surfactant is necessary. Alterations in gene and aberrant expression of the protein are implicated and detected in carcinomas of different origin (ovarian, esophageal) modifying clinicpathological parameters, even survival rates due to advanced stage and metastatic potential in the corresponding patients $(9,10)$. Especially in esophageal carcinoma, SPLA2 seems to act as a functional ligand for the epidermal growth factor receptors (type I and II) enhancing the corresponding receptor mediated signaling transduction to the nucleus. In the current study, we explored the role of SPLA2 protein expression in a series of CAs in order to reveal a potential association with specific clinic-histopathological features of the examined cases.

\section{Materials and Methods}

Study group. For the purposes of our study, thirty $(\mathrm{n}=30)$ archival, formalin-fixed and paraffin-embedded tissue specimens of histologically confirmed primary CAs were used. The hospital ethics committee consented to the use of these tissues (Department of Pathology, Halkida General Hospital, Greece) for research purposes, according to World Medical Association Declaration of Helsinki guidelines. The tissue samples were fixed in $10 \%$ neutralbuffered formalin. Hematoxylin and eosin (H\&E)-stained slides of the corresponding samples were reviewed for establishing the corresponding histopathological diagnoses. All lesions were classified according to the histological typing and staging criteria of World Health Organization (WHO) digestive system tumors classification (11). Clinicopathological data of the examined cases are presented in Table I.

Antibodies and immunohistochemistry assay (IHC). We used the rabbit polyclonal anti-SphA2 (ab23705, Abcam, Cambridge, UK; dilution/concentration at $5 \mu \mathrm{g} / \mathrm{ml}$ ) antibody. The IHC protocol for the antigen detection was carried out on a $3 \mu$ m-thick paraffin sections. Tissue sections initially de-paraffinized in xylene and rehydrated via graded ethanol - were immunostained according to the EN Vision ${ }^{+}$ (DAKO, Glostrup, Denmark) assay using an automated staining system (I 6000 - Biogenex, Fremont, CA, USA) and according to the manufacturer's instructions. This assay is based on a soluble, dextranpolymer system preventing endogenous biotin reaction and increasing the quality of the stained slides. Briefly, the sections were pre-treated with sodium-based citrate buffer for $25 \mathrm{~min}$ as a heat mediated antigen retrieval. Then, they were incubated with the primary antibody for $15 \mathrm{~min}$ at room temperature followed by detection with a Horseradish peroxidase labeled polymer-HRP LP system. A wash with TBS was performed. The antigen-antibody reaction was visualized using 3-3, diaminobenzidine tetrahydrocloride (DAB) as a chromogenic substrate ( $8 \mathrm{~min}$ at room temperature). Finally, the tissue sections were slightly counterstained with hematoxylin for $30 \mathrm{~s}$, dehydrated and mounted with Dibutylphthalate Polysterene Xylene (DPX: Thermo Shandon Limited, Cheshire, UK). For the negative control, the primary antibody was omitted. Focal or diffuse membranous and cytoplasmic/sub-membranous staining patterns were
Table I. Intraoperative details of the patients submitted to en bloc pancreatic and vascular resections.

\begin{tabular}{|c|c|c|c|c|}
\hline \multirow{2}{*}{\multicolumn{2}{|c|}{$\begin{array}{l}\text { Clinicopathological } \\
\text { parameters } \\
\text { CAs }(n=30)\end{array}$}} & \multicolumn{2}{|c|}{ SPLA2 } & \multirow[t]{2}{*}{$p$-Value } \\
\hline & & $\mathrm{OE}$ & LE & \\
\hline \multicolumn{5}{|c|}{$23 / 30(76.6 \%)$} \\
\hline Gender & & & & 0.369 \\
\hline Male & $15(50 \%)$ & $13(42.9 \%)$ & $2(6.6 \%)$ & \\
\hline Female & $15(50 \%)$ & $10(33.3 \%)$ & $5(16.4 \%)$ & \\
\hline Grade & & & & 0.748 \\
\hline I & $1(3.3 \%)$ & $1(3.3 \%)$ & $0(0 \%)$ & \\
\hline II & $22(73.3 \%)$ & $16(52.8 \%)$ & $6(19.9 \%)$ & \\
\hline III & $7(23.3 \%)$ & $6(19.9 \%)$ & $1(3.3 \%)$ & \\
\hline Stage & & & & 0.971 \\
\hline I & $3(10 \%)$ & $3(10 \%)$ & $0(0 \%)$ & \\
\hline II & $13(43.3 \%)$ & $10(33.3 \%)$ & $3(10 \%)$ & \\
\hline III & $10(33.3 \%)$ & $7(23.3 \%)$ & $3(10 \%)$ & \\
\hline IV & $4(13.3 \%)$ & $3(10 \%)$ & $1(3.3 \%)$ & \\
\hline $\begin{array}{l}\text { Anatomical } \\
\text { location }\end{array}$ & & & & 0.340 \\
\hline Sigmoid & $13(43.3 \%)$ & $11(36.3 \%)$ & $2(6.6 \%)$ & \\
\hline Rectum & $8(13.3 \%)$ & $6(19.8 \%)$ & $2(6.6 \%)$ & \\
\hline $\begin{array}{l}\text { Ascending- } \\
\text { Caecum }\end{array}$ & $9(23.3 \%)$ & $6(19.8 \%)$ & $3(10 \%)$ & \\
\hline $\begin{array}{l}\text { Inflammatory } \\
\text { infiltration }\end{array}$ & & & & 0.795 \\
\hline Yes & $25(83.5 \%)$ & $20(66 \%)$ & $5(16.5 \%)$ & \\
\hline No & $5(16.7 \%)$ & $3(10 \%)$ & $2(6.7 \%)$ & \\
\hline Ulceration & & & & 0.433 \\
\hline Yes & $5(16.5 \%)$ & $4(13.2 \%)$ & $1(3.3 \%)$ & \\
\hline No & $25(83.5 \%)$ & $19(62.7 \%)$ & $6(19.8 \%)$ & \\
\hline $\begin{array}{l}\text { Diameter } \\
\max (\mathrm{cm})\end{array}$ & & & & 0.040 \\
\hline$<4$ & $14 / 30(47.2 \%)$ & $12(39.6 \%)$ & $2(6.6 \%)$ & \\
\hline$\geq 4$ & $16 / 30(52.8 \%)$ & $11(36.3 \%)$ & $5(16.5 \%)$ & \\
\hline
\end{tabular}

CAs: Colon adenocarcinomas; SPLA2: secretory phospholipase A2; OE: over-expression (high/moderate expression), staining intensity values $\leq 137$; LE: low expression, staining intensity values $>141$. Bold $p$-Value shows statistical significance.

acceptable for the marker's expression (Figure 1). Normal colon epithelial tissue sections were used as positive markers for its immunostaining pattern, according to the antibody's manufacturer instructions.

Digital image analysis assay (DIA). SPLA2 protein expression levels were evaluated quantitatively by estimating the corresponding staining intensity levels (densitometry evaluation) in the stained malignant cells. We performed DIA using a semi-automated system [hardware: Microscope CX-31, (Olympus, Melville, NY, USA) equipped with a Digital camera (Sony, Tokyo, Japan); Windows XP/NIS-Elements Software AR v3.0, (Nikon Corp, Tokyo, Japan)]. Areas of interest per tissue section were identified (5 optical fields at $\times 400$ magnification) and filed in a digital database as snapshots. Measurements were performed by implementing a specific macro (diffuse membranous and cytoplasmic/sub-membranous expression 


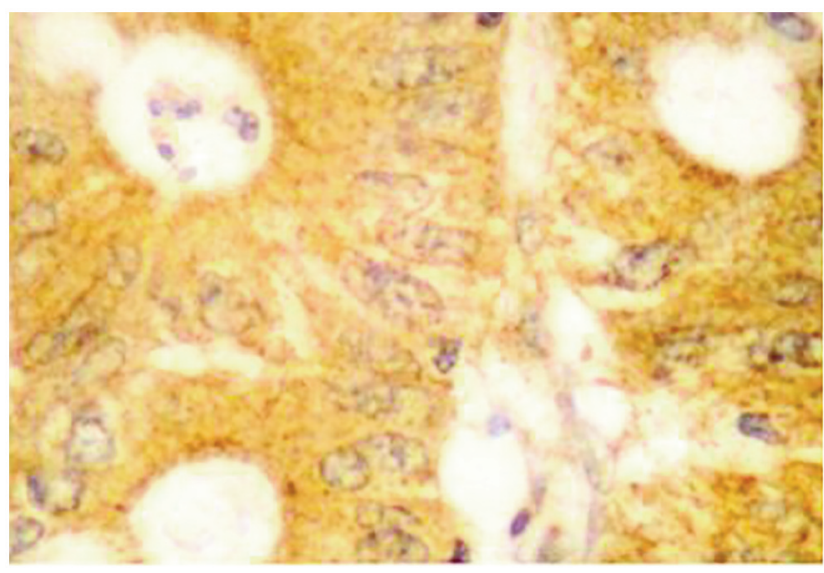

Figure 1. SPLA2 protein expression in colon adenocarcinoma. High SPLA2 protein expression presented as strong diffuse membrane/cytoplasmic brown staining pattern; anti-secretory phospholipase A2 (SPLA2), diaminobenzidine tetrahydrochloride (DAB) staining, original magnification: 100x

for tumor cells, according to manufacturer's datasheet). Based on an algorithm, intensity of staining of normal tissue sections (control) was measured independently and compared to the corresponding values in malignant tissue sections. A broad spectrum of continuous grey scale values (0-255) at the RedGreenBlue (RGB) analysis was available for discriminating different protein expression levels. In this digitized process, immunostaining intensity values decreasing to 0 are considered as a progressive over-expression of the marker, whereas values increasing to 255 show a progressive loss of the staining intensity. All results and DIA values are shown in Table I.

Statistical analysis. For statistical analyses, descriptive and inferential tests were applied. Quantitative variables are presented as mean \pm standard deviation, while the qualitative variables are presented in frequency tables. To evaluate the relationship between qualitative and quantitative variables, because of the small number of subjects in each group, the non-parametric Mann-Whitney, Kruskall-Wallis, and also Fisher tests were applied. Statistical significance $(p)$ was evaluated in pairs and differences $<0.05$ were considered statistically significant. All IHC results and differences ( $p$-values) are shown in Table I.

\section{Results}

According to digital expression analysis, the examined immunostained CA tissue sections demonstrated different expression levels of the SPLA2 marker. SPLA2 protein over expression (increased immunostaining levels, including high \& moderate) was observed in $23 / 30(76.6 \%)$ cases, whereas $7 / 30(23.4 \%)$ CA tissues demonstrated low protein levels. High expression levels were detected in 9/30 (30\%) of the analyzed cases. SPLA2 overall expression was strongly associated with the tumor diameter $(p=0.004)$, whereas no other statistically significant associations were observed

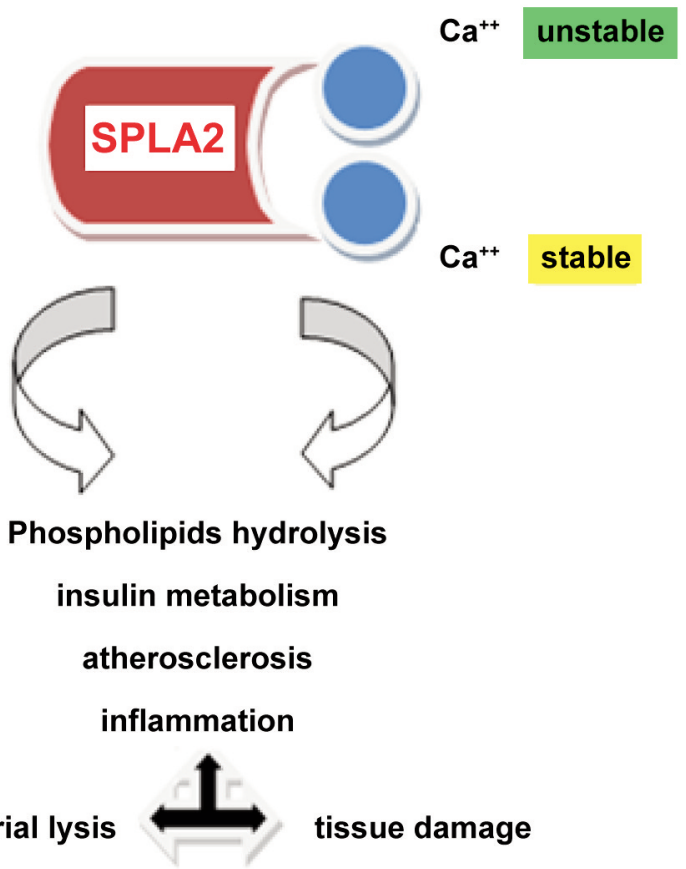

Figure 2. Schematic representation of anti-secretory phospholipase A2 (SPLA2) functions. Phospholipase enzymes' family is involved in crucial intracellular metabolic activities. SPLA2 protein - as a calcium dependent enzyme- is implicated in various biological reactions affecting lipid metabolism and inflammation. Interestingly at the biochemical level, its second calcium binding site is unstable, affecting the whole catalytic mechanism of the molecule.

(stage: $p=0.971$; inflammatory infiltration: $p=0.795$; carcinoma location: $p=0.340$; differentiation grade: $p=0.748$; sex: $p=0.369$; ulceration: $p=0.433$ ). In fact, SPLA2 over-expression is involved in the volume progression of the neoplasm.

\section{Discussion}

Phospolipase enzymes' family modifies crucial intracellular metabolic activities. Especially, SPLA2 protein - as a calcium dependent enzyme- is implicated in various biological reactions affecting lipid metabolism and inflammation (Figure 2). Interestingly - at the biochemical level- one of the two calcium binding sites is unstable, affecting the catalytic mechanism of the molecule (12). In the current study, we explored SPLA2 expression in a series of CA tissues. We observed that high levels of SPLA2 correlated strongly to tumor growth (increased diameter). Very limited data are available concerning SPLA2 gene deregulation and the impact of aberrant expression of SPLA2 on CA biological behavior compared to normal epithelia. Differences in SPLA2 expression have been detected in a study examining its expression by IHC in the gastrointestinal tract, gall bladder, and pancreatic acinar cells (13). Over-expression of SPLA2 was observed in Crohn's 
disease and ulcerative colitis, whereas colonic adenomas and carcinomas demonstrated varying intensity levels. Similarly, another study group revealed elevated SPLA2 expression analyzing a set of sporadic CAs tissues by implementing quantitative polymerase chain reaction (PCR) (14). They also focused on the SPLA2-III variant and its potential role in CA onset and progression for both left and right colon anatomical locations. Besides these molecular observations, another study detected increased levels of SPLA2-IIA expression by western blotting in peripheral compared to core regions of malignant tissues. This unique pattern of expression in peripheral and central sites of the examined malignancies, may affect tumor micro-environment and immunology response status in the corresponding patients (15). Furthermore, studies in cell lines (such as human colon carcinoma cell line HCT-116/murine colon tumor cell line $\mathrm{AJ} 02 \mathrm{~nm} 0$ ) revealed a potential relation of specific SPLA2 allelic variants in different tissue substrates (16). Because the enzyme acts as a key regulator of lipid droplets formation, another study explored its role in lipid droplet accumulation in colon cancer cell lines. They detected differences in extracellular/intracellular phospholipases, but the exact mechanism of their implication in CA development and progression is still under investigation (17). The involvement of SPLA2 in CA neo-angiogenesis, invasion/metastasis, and deregulated cell proliferation/apoptosis pathways is another target for research. A study group focused on its role in the synthesis and supply of arachidonic acid (AA) and its impact on COX-2-dependent prostaglandin signaling pathway. They reported that hypertonic stress increased SPLA2 activity leading to COX-2 induction (18). Similarly, another experimental study based on mouse colon carcinoma cell lines showed an inverse relation between COX-2 and cytosolic SPLA2. Involvement of TNF-alpha-mediated apoptosis in tumor progression was also observed $(19,20)$. A study group analyzed an expanded set of polymorphisms in order to detect specific SPLA2-related genetic signatures in a series of CAs combined with other genes. They concluded that the genetic variability of the PLA2G3 CT haplotype was significantly correlated to a higher risk for CA in the corresponding carriers (21). Similar SPLA2 gene and protein imbalances that affect crucial metabolic pathways have already been detected in lung and gynecological carcinomas including breast and ovarian cancer. Interestingly, aberrant SPLA2 protein expression affects epithelial to mesenchymal transition in these cacners (22-26).

In conclusion, SPLA2 overexpression is observed in a significant subset of CAs correlating with aggressive biological behavior (progressive growth of malignant tumor). It is a crucial enzyme for cell response and metabolic homeostasis and also an interesting protein that cab potentially be a biomarker and therapeutic target $(27,28)$. Although the current study included a relatively limited number of specimens for SPLA2 protein analysis, it seems that different grade and stage intensity levels may provide some information regarding the relationship between SPLA2 expression and cancer progression. Further genetic and protein-based studies on the molecule's deregulation mechanisms in cancerous and non-cancerous colon epithelia could reveal unexplored intra-cellular pathways regarding its interactions with other metabolic regulators.

\section{Conflicts of Interest}

The Authors declare no conflicts of interest regarding this study.

\section{Authors' Contributions}

Evangelos Falidas, Eirini Kitsiouli, Evangelos Tsiambas, Asimina Kalogirou: research, article writing-formatting, George Tsouvelas: statistics, Stylianos Papadopoulos, Michail Mitsis, Marilena Lekka, Sofianiki Mastronikoli, Odysseas Dimas: specimen collection, clinic-pathologic feature stratification, reference detection, Dimitrios Peschos, Despoina Spyropoulou Konstantinos Vlachos: academic advisor, article review.

\section{References}

1 Hanahan D and Weinberg RA: Hallmarks of cancer: the next generation. Cell 144(5): 646-674, 2011. PMID: 21376230. DOI: 10.1016/j.cell.2011.02.013

2 Morales AM, Mukai R, Murota K and Terao J: Inhibitory effect of catecholic colonic metabolites of rutin on fatty acid hydroperoxide and hemoglobin dependent lipid peroxidation in Caco-2 cells. J Clin Biochem Nutr 63(3): 175-180, 2018. PMID: 30487666. DOI: $10.3164 /$ jcbn.18-38

3 Casale J, Kacimi SEO and Varacallo M: Biochemistry, Phospholipase A2. In: StatPearls [Internet]. Treasure Island, FL, U.S.A., StatPearls Publishing, 2021. PMID: 30521272.

4 Manukyan AK: Structural aspects and activation mechanism of human secretory group IIA phospholipase. Eur Biophys J 49(6): 511-531, 2020. PMID: 32852622. DOI: 10.1007/s00249-02001458-5

5 Brglez V, Lambeau G and Petan T: Secreted phospholipases A2 in cancer: diverse mechanisms of action. Biochimie 107 Pt A: 114123, 2014. PMID: 25286228. DOI: 10.1016/j.biochi.2014.09.023

6 Zhang S, Gong W, Han Z, Liu Y and Li C: Insight into shared properties and differential dynamics and specificity of secretory phospholipase $\mathrm{A}_{2}$ family members. J Phys Chem B 125(13): 33533363, 2021. PMID: 33780247. DOI: 10.1021/acs.jpcb.1c01315

7 Kuefner MS: Secretory phospholipase A2s in insulin resistance and metabolism. Front Endocrinol (Lausanne) 12: 732726, 2021. PMID: 34512555. DOI: 10.3389/fendo.2021.732726

8 De Luca D, Shankar-Aguilera S, Autilio C, Raschetti R, Vedovelli L, Fitting C, Payré C, Jeammet L, Perez-Gil J, Cogo PE, Carnielli VP, Lambeau G and Touqui L: Surfactant-secreted phospholipase $\mathrm{A}_{2}$ interplay and respiratory outcome in preterm neonates. Am J Physiol Lung Cell Mol Physiol 319(1): L95-L104, 2020. PMID: 32401671. DOI: 10.1152/ajplung.00462.2019

9 Ray U, Roy D, Jin L, Thirusangu P, Staub J, Xiao Y, Kalogera E, Wahner Hendrickson AE, Cullen GD, Goergen K, Oberg AL and Shridhar V: Group III phospholipase A2 downregulation attenuated survival and metastasis in ovarian cancer and promotes 
chemo-sensitization. J Exp Clin Cancer Res 40(1): 182, 2021. PMID: 34082797. DOI: 10.1186/s13046-021-01985-9

10 Halpern AL, Kohtz PD, White AM, Houk AK, Rehring JF, Hanson L, McCarter MD, Joshi M, Meng X, Fullerton DA and Weyant MJ: Secretory phospholipase A2 IIa mediates expression of growth factor receptors in esophageal adenocarcinoma. Dig Dis Sci 66(3): 784-795, 2021. PMID: 32277371. DOI: 10.1007/ s10620-020-06241-2

11 Nagtegaal ID, Odze RD, Klimstra D, Paradis V, Rugge M, Schirmacher P, Washington KM, Carneiro F, Cree IA and WHO Classification of Tumours Editorial Board: The 2019 WHO classification of tumours of the digestive system. Histopathology 76(2): 182-188, 2020. PMID: 31433515. DOI: 10.1111/his.13975

12 Hou S, Bai J, Chen C, Zhang X, Chang F, Cao Z, Xu T and Xie J: The atypical binding mechanism of second calcium on phospholipase A2 group IIE. Biochem Biophys Res Commun 557: 267-272, 2021. PMID: 33894413. DOI: 10.1016/j.bbrc.2021.04.030

13 Peuravuori H, Kollanus S and Nevalainen TJ: Expression of group XIIA phospholipase A2 in human digestive organs. APMIS 122(12): 1171-1177, 2014. PMID: 24862647. DOI: 10.1111/apm.12280

14 Mounier CM, Wendum D, Greenspan E, Fléjou JF, Rosenberg DW and Lambeau G: Distinct expression pattern of the full set of secreted phospholipases A2 in human colorectal adenocarcinomas: sPLA2-III as a biomarker candidate. Br J Cancer 98(3): 587-595, 2008. PMID: 18212756. DOI: 10.1038/sj.bjc.6604184

15 Tribler L, Jensen LT, Jørgensen K, Brünner N, Gelb MH, Nielsen HJ and Jensen SS: Increased expression and activity of group IIA and $\mathrm{X}$ secretory phospholipase A2 in peritumoral versus central colon carcinoma tissue. Anticancer Res 27(5A): 3179-3185, 2007. PMID: 17970059.

16 Belinsky GS, Rajan TV, Saria EA, Giardina C and Rosenberg DW: Expression of secretory phospholipase A2 in colon tumor cells potentiates tumor growth. Mol Carcinog 46(2): 106-116, 2007. PMID: 17091473. DOI: $10.1002 / \mathrm{mc} .20271$

17 Yap WH, Phang SW, Ahmed N and Lim YM: Differential effects of $\mathrm{sPLA}_{2}-\mathrm{GV}$ and $\mathrm{GX}$ on cellular proliferation and lipid accumulation in HT29 colon cancer cells. Mol Cell Biochem 447(1-2): 93-101, 2018. PMID: 29374817. DOI: 10.1007/ s11010-018-3295-y

18 Gentile LB, Piva B, Capizzani BC, Furlaneto LG, Moreira LS, Zamith-Miranda D and Diaz BL: Hypertonic environment elicits cyclooxygenase-2-driven prostaglandin E2 generation by colon cancer cells: role of cytosolic phospholipase A2-alpha and kinase signaling pathways. Prostaglandins Leukot Essent Fatty Acids 82(2-3): 131-139, 2010. PMID: 20004562. DOI: 10.1016/j.plefa. 2009.11.005

19 Dong M, Guda K, Nambiar PR, Rezaie A, Belinsky GS, Lambeau G, Giardina C and Rosenberg DW: Inverse association between phospholipase A2 and COX-2 expression during mouse colon tumorigenesis. Carcinogenesis 24(2): 307-315, 2003. PMID: 12584182. DOI: 10.1093/carcin/24.2.307

20 Dong M, Johnson M, Rezaie A, Ilsley JN, Nakanishi M, Sanders MM, Forouhar F, Levine J, Montrose DC, Giardina C and Rosenberg DW: Cytoplasmic phospholipase A2 levels correlate with apoptosis in human colon tumorigenesis. Clin Cancer Res 11(6): 2265-2271, 2005. PMID: 15788676. DOI: 10.1158/10780432.CCR-04-1079

21 Hoeft B, Linseisen J, Beckmann L, Müller-Decker K, Canzian F, Hüsing A, Kaaks R, Vogel U, Jakobsen MU, Overvad K,
Hansen RD, Knüppel S, Boeing H, Trichopoulou A, Koumantaki Y, Trichopoulos D, Berrino F, Palli D, Panico S, Tumino R, Bueno-de-Mesquita HB, van Duijnhoven FJ, van Gils $\mathrm{CH}$, Peeters PH, Dumeaux V, Lund E, Huerta Castaño JM, Muñoz X, Rodriguez L, Barricarte A, Manjer J, Jirström K, Van Guelpen B, Hallmans G, Spencer EA, Crowe FL, Khaw KT, Wareham N, Morois S, Boutron-Ruault MC, Clavel-Chapelon F, Chajes V, Jenab M, Boffetta P, Vineis P, Mouw T, Norat T, Riboli E and Nieters A: Polymorphisms in fatty-acid-metabolism-related genes are associated with colorectal cancer risk. Carcinogenesis 31(3): 466-472, 2010. PMID: 20042636. DOI: 10.1093/carcin/ bgp325

$22 \mathrm{Xu}$ W, Xu Q, Kuang D, Wang Z, Lu Q, Lin Q, Wu H and Chen L: Long non coding RNA SLNCR1 regulates non small cell lung cancer migration, invasion and stemness through interactions with secretory phospholipase A2. Mol Med Rep 20(3): 25912596, 2019. PMID: 31524254. DOI: $10.3892 / \mathrm{mmr} .2019 .10518$

23 Halpern AL, Kohtz PD, Rove JY, Ao L, Meng X, Fullerton DA and Weyant MJ: Inhibition of secretory phospholipase A2 IIa attenuates prostaglandin E2-induced invasiveness in lung adenocarcinoma. Mol Cell Biochem 456(1-2): 145-156, 2019. PMID: 30684134. DOI: 10.1007/s11010-019-03500-3

24 Najahi-Missaoui W, Quach ND, Somanath PR and Cummings BS: Liposomes targeting P21 activated kinase-1 (PAK-1) and selective for secretory phospholipase $\mathrm{A}_{2}\left(\mathrm{sPLA}_{2}\right)$ decrease cell viability and induce apoptosis in metastatic triple-negative breast cancer cells. Int J Mol Sci 21(24): 9396, 2020. PMID: 33321758. DOI: $10.3390 /$ ijms 21249396

25 Jespersen SS, Stovgaard ES, Nielsen D, Christensen TD, Buhl ASK, Christensen IJ and Balslev E: Expression of secretory phospholipase A2 group IIa in breast cancer and correlation to prognosis in a cohort of advanced breast cancer patients. Appl Immunohistochem Mol Morphol 29(1): e5-e9, 2021. PMID: 32217848. DOI: 10.1097/PAI.0000000000000854

26 Tang M, Jiang L, Lin Y, Wu X, Wang K, He Q, Wang X and Li W: Platelet microparticle-mediated transfer of miR-939 to epithelial ovarian cancer cells promotes epithelial to mesenchymal transition. Oncotarget 8(57): 97464-97475, 2017. PMID: 29228624. DOI: 10.18632/oncotarget.22136

27 Pourhassan H, Clergeaud G, Hansen AE, Østrem RG, Fliedner FP, Melander F, Nielsen OL, O'Sullivan CK, Kjær A and Andresen TL: Revisiting the use of PLA $_{2}$-sensitive liposomes in cancer therapy. J Control Release 261: 163-173, 2017. PMID: 28662900. DOI: 10.1016/j.jconrel.2017.06.024

28 Abdelgawad MA, Bakr RB, Ahmad W, Al-Sanea MM and Elshemy HAH: New pyrimidine-benzoxazole/benzimidazole hybrids: Synthesis, antioxidant, cytotoxic activity, in vitro cyclooxygenase and phospholipase A2-V inhibition. Bioorg Chem 92: 103218, 2019. PMID: 31536956. DOI: 10.1016/ j.bioorg.2019.103218 